\title{
Reticence in Chinese EFL Students at Varied Proficiency Levels
}

\section{Meihua Liu and Jane Jackson}

Reticence in foreign language classes has long been a challenge for both teachers and students. With the advent of globalization, there is a pressing need for EFL (English as a Foreign Language) teachers to help reticent students develop the skills and confidence needed to take an active role in oral English lessons. This article reports on a study of reticence in EFL classrooms in a key university in Beijing. Five hundred, forty-seven first-year non-English majors with three proficiency levels answered a 124-item questionnaire with 20 items on reticence. In addition, one class from each proficiency group was selected for a more focused investigation of reticence and participation in oral EFL lessons. As well as the survey, data gathered during the 14-week term included reflective journals, videotaped observations, and interviews. Analyses of the data revealed that (a) the students were willing to communicate with their peers in English in class and considered speech communication valuable; the more proficient were most positive about interpersonal communication and the most willing to engage in interaction; (b) all the students, irrespective of proficiency level, were the most active during pair work and the least active when responding to teachers' questions; the more proficient students tended to be the most active in all classroom activities; and (c) with increased exposure to spoken English and more familiarity with the English-learning environment, students at all proficiency levels became (more) active in class. Based on the findings, pedagogical implications are discussed with the aim of enhancing the teaching and learning of spoken English in foreign-language contexts.

La réticence dans les cours de langue étrangère pose, depuis longtemps, un défi tant pour les enseignants que les élèves. La mondialisation accroît le besoin pressant d'enseignants d'anglais langue étrangère (ALE) qui puissent aider les élèves réticents à développer les aptitudes et la confiance qui leur faut pour jouer un rôle actif dans les leçons d'anglais oral. Cet article porte sur une étude de la réticence dans des cours d'ALE dans une grande université à Beijing. Cinq cent quarante-sept étudiants en première année qui ne se spécialisaient pas en anglais et qui étaient répartis parmi trois niveaux de compétence dans cette langue ont répondu à un questionnaire. Vingt des cent vingt-quatre items du questionnaire portaient sur la réticence. De plus, on a choisi un groupe de chaque niveau de compétence pour une enquête plus poussée de la réticence et la participation aux cours d'oral en ALE. Des données recueillies pendant le semestre de 14 semaines sont venues s'ajouter à ceux de l'enquête: des journaux réflexifs, des observations 
filmées et des entrevues. L'analyse des données a révélé que (a) les étudiants étaient prêts à communiquer en anglais avec leurs pairs en classe et ils estimaient que la communication orale était importante; les étudiants les plus compétents en anglais se montraient plus positifs par rapport à la communication interpersonnelle et plus disposés à interagir avec les autres; (b) tous les étudiants, indépendamment de leur niveau de compétence, étaient le plus actifs pendant le travail en groupe de deux et le moins actifs quand ils répondaient aux questions de l'enseignant; les étudiants les plus compétents étaient généralement les plus actifs lors de toutes les activités du cours; et (c) plus les étudiants étaient exposés à l'anglais parlé et plus ils étaient à l'aise dans un milieu d'apprentissage de l'anglais, plus ils devenaient actifs en classe; ce constat est valide pour tous les étudiants, peu importe leur niveau de compétence. Les auteurs arrivent à des répercussions pédagogiques à partir de ces résultats et les présentent dans le but d'améliorer l'enseignement et l'apprentissage de l'anglais oral dans des milieux de langues étrangères.

\section{Introduction}

Although not extensively researched, reticence has been receiving increasing attention in recent decades due to the growing importance of oral proficiency in second- and foreign-language learning situations (Chen, 2003; Flowerdew, Miller, \& Li, 2000; Jackson, 1999, 2001; MacIntyre, Baker, Clément, \& Conrod, 2001; Tsui, 1996; Zou, 2004). By way of interviews, observations and/or journals, and surveys, research has revealed that second/foreign-language learners, especially Asian learners, often seem passive and reticent in language classrooms. Some rarely respond to their teachers or actively participate in discussions. What accounts for this phenomenon? What can be done to help students take a more active role?

Researchers have discovered various reasons for this reluctance to speak in foreign-language classroom situations: fear of losing face (e.g., making mistakes and being laughed at); low proficiency in the target language; previous negative experiences with speaking in class; cultural beliefs about appropriate behavior in classroom contexts (e.g., the importance of showing respect by listening to the teacher instead of speaking up); incomprehensible input, habits (e.g., becoming used to a passive role in the classroom); and lack of confidence (e.g., in ideas or in language) and personality (e.g., introversion). The specific causes for student reticence have also been found to vary according to the context. Focusing on Mainland Chinese university students with varied levels of proficiency in English, this study explored factors affecting reticence and participation in oral English-language lessons. 


\section{Literature Review}

To set the stage for this study, it is important to review the methods and findings of earlier research that has explored the reticence phenomenon, especially in other Asian contexts. In Hong Kong, Tsui (1996), for example, reviewed the classroom action research project reports of 38 Hong Kong English-language teachers to better understand student reticence and anxiety. The teachers videotaped or audiorecorded their own lessons and analyzed the tapes to identify specific problems in their teaching. Most noticed that their students were quiet during their lessons, and over $70 \%$ commented that stimulating student oral responses was one of their greatest challenges.

Tsui (1996) found that most of the teachers attributed students' reticence to low English proficiency; as one teacher explained, "I think the students' failure to respond to teachers' question was a result less from lack of knowledge but more of the insufficient English proficiency" (p. 148). The second reason commonly mentioned was students' lack of confidence and fear of making mistakes and being laughed at. Consequently, the students were reluctant to answer in front of the whole class, and when called on by their teacher spoke in a barely audible voice. The teachers' intolerance of silence was also considered a factor. Many teachers reported that they themselves disliked or were afraid of silence; they felt uneasy or impatient when failing to gain a response from students. Thus when no response was forthcoming, teachers would repeat or modify the question, quickly ask another student, or provide the answer themselves. In addition, uneven allocation of turns and incomprehensible input appeared to promote reticence. In this climate the students who were singled out for questions seemed to feel under pressure.

In general, Tsui's (1996) findings have been supported by a number of other studies of foreign-language classroom situations (including contentbased contexts) either in Hong Kong (Flowerdew et al., 2000; Jackson, 2001, 2003; Liu \& Littlewood, 1997), Mainland China (Cortazzi \& Jin, 1996; Zou, 2004), or Thailand (Thein, 1994). In Jackson's (1999) and Liu and Littlewood's studies, the students expressed willingness to participate in classroom discussions in the target language, but remained reticent and passive in class. Some students in Jackson's (2002) study even perceived themselves as active in class just by listening to others.

Clearly, as Jackson (2003) claims, reticence is a complicated phenomenon in target-language medium classrooms, as it is provoked by a complex set of cultural, linguistic, psychological, and social factors. Thus it is important to explore this issue in more depth so as to help students become more active learners in second- or foreign-language learning contexts, especially foreignlanguage (FL) situations. Given the scarcity of research in this area in Main- 
land China, we undertook this study in Beijing to investigate students' reticence in oral English lessons at the tertiary level. To achieve this aim, the following research questions guided the research.

1. To what extent do Mainland Chinese students experience reticence in oral English classrooms?

2. What is the difference in reticence among students at different proficiency levels? What accounts for these differences?

3. In which classroom activity are students the most reticent?

4. Is there any change in student reticence in different activities over the term? If yes, why?

\section{Research Methodology}

In this article we report on one phase of a larger investigation of student reticence and anxiety in both oral English classroom-learning and testing situations in a key comprehensive university in Beijing (Liu, 2006a, 2006b, 2007; Liu \& Jackson, 2007, 2008).

\section{Participants}

Five hundred, forty-seven (430 male and 117 female) first-year non-English majors enrolled in the English Listening and Speaking course at three band ${ }^{1}$ levels were recruited to answer a battery of questionnaires. Among these respondents 166 were band 1 students, 224 band 2 students, and 157 band 3 students. With an age range of 14-21 and an average age of 18.4, these students had started to learn English at an age range of 3-16 and spoken English at an age range of 3-20.

In order to explore further the issue of reticence in classrooms, three classes that answered the survey were selected for closer scrutiny, with one class from each band level: 34 band 1 students, 32 band 2 students, and 34 band 3 students. This more focused phase of the study continued for a full 14-week term.

\section{Instruments}

To investigate students' reticence in English-language classrooms at varied proficiency levels, a triangulation of methods was adopted. Data sources included surveys (reticence and background questionnaires), observations, reflective journals, and semistructured interviews as detailed below.

\section{The Unwillingness-to-Communicate Scale}

To measure reticence in speech communication, Burgoon (1976) developed the 24-item Unwillingness-to-Communicate Scale (UCS), which measures two dimensions of communication reticence: approach-avoidance (AA) and reward (R). Burgoon and Koper (1984) describe them as follows. 
The AA dimension represents an individual's tendency to avoid or participate in interpersonal and small group interactions.[...] The $R$ dimension, by contrast, reflects attitudes toward communicationwhether one considers it a valuable, honest, and personally rewarding enterprise or feels socially isolated and regards communication as a deceptive, manipulative, or unprofitable activity. (pp. 608-609)

In the present study, the 20-item (10 items for AA and 10 items for R) short form of the UCS was used to measure students' general tendency to avoid speech communication. Using a 5-point Likert scale ranging from 1=Strongly Disagree to 5=Strongly Agree, all the items were translated into Chinese and pilot-tested to ensure comprehensibility.

\section{Background Questionnaire}

The background questionnaire was designed to gather demographic data about the participants such as their name, sex, age, and department, Englishlearning time, access to English, and self-rated proficiency in English.

\section{Teacher Observation}

The teachers of the three focal classes were asked to keep a weekly record of their students' behavior and anxiety level in various classroom activities during the whole term (e.g., noting the most/least active, silent, confident and/or anxious).

\section{Reflective Journal}

To gather additional data about personal and affective variables in languagelearning, the students in three focal classes were asked to write reflective journals weekly for six successive weeks. In addition to bilingual (ChineseEnglish) prompts related to the focal topics (e.g., level of participation and anxiety in each lesson and reasons for being reticent and feeling anxious), the students were encouraged to write about their language-learning experiences in either Chinese or English.

\section{Semistructured Interviews}

To develop a more comprehensive insider view of reticence in English language classrooms, two high-reticent, three average-reticent, and two lowreticent students from each band class, as well as their three teachers, were invited to individual semistructured interviews. Questions for students covered such aspects as educational experience, participation in university English lessons, self-ratings of their oral English proficiency, reasons for being reticent, and coping strategies. To complement students' perceptions, questions for the teachers focused on their identification of the most reticent/active, confident/anxious students in various classroom activities, general reasons for student reticence and anxiety, and coping strategies. All 
interview protocols were translated into Chinese so that interviews could be conducted in that language in accordance with the wishes of the interviewees.

\section{Classroom Observation}

To compare the students' self-reports with teachers' perceptions, the three focal classes were observed and videotaped on three separate occasions during the term by the first author. These videotaped observations centered on the students' levels of participation, anxiety, and performance in various oral classroom activities: pair work, group discussion, presentations, and answering teachers' questions.

\section{Procedure}

The study was conducted during the first 14-week term of 2003-2004. The students started journal writing in the second week and continued for six successive weeks with one entry per week. The teachers kept a weekly record of their students' reticence and anxiety in various classroom activities from the second to the 12th week. The students were asked to answer the survey in 20 minutes at the beginning of a normal teaching period in the second half of the term. The semistructured interviews took place toward the end of the term. Each student interview lasted about 50 minutes and each teacher interview 30 minutes; both were conducted in Mandarin Chinese and audiotaped.

During the last two months of the term, the first author observed and videotaped each focal class three times with a focus on oral activities; each session lasted 90 minutes. The videotaping aimed to obtain a general picture of what was happening in the class and to provide insight into individual students' performance in various activities. Videotaping was done three times throughout the term so that the students would behave as naturally as possible in the presence of the equipment; moreover, only the final two videotapings were used for data analysis.

\section{Data Analysis}

SPSS was used to compute descriptive statistics for the survey. The frequency and percentage for each item, and the mean, standard deviation, mode, median, and range for the scale were obtained to provide an indication of the students' reticence levels for the group as a whole as well as for those at various proficiency levels. An ANOVA analysis was conducted to explore differences in reticence at various proficiency levels. The interviews were transcribed and checked twice. Together with the journals and observations, they were then subjected to a thematic content analysis (Krippendorff, 1980). The first author coded all the qualitative data, and a second coder coded $25 \%$. The intercoder reliability was .88 . 


\section{Results and Discussion}

Reticence Level

Analysis of the Unwillingness-to-Communicate Scale. With a reliability score of .84 in this research, the UCS measured the extent to which the students remained unwilling to communicate in oral English classrooms. Table 1 presents the students' responses to the UCS items, which reflect unwillingness to participate in speech communication. The first number presents the actual score and the second the percentage. All percentages refer to the number of students who strongly disagreed or strongly agreed with the statements (percentages were rounded to the nearest whole number).

As can been seen from Table 1, many respondents expressed positive attitudes toward speech communication (e.g., group discussions and interaction). They agreed with statements like I like to get involved in group discussions (item 4, 46.7\%), and rejected statements like I avoid group discussions (item 8, $71.3 \%$ ). The students seemed to be aware of the benefits of talking to others, and more than $70 \%$ rejected the statement Talking to other people is just a waste of time (item 20).

As Table 1 illustrates, more than half the students believed in the honesty and sincerity of their friends and sought their friends' and family members' opinions when making decisions. For example, $70.5 \%$ endorsed the statement I think my friends are truthful with me (item 13), and $72.4 \%$ agreed with the statement My friends and family listen to my ideas and suggestions (item 17), whereas $74.7 \%$ objected to the statement I don't ask for advice from family or friends when I have to make decisions (item 14). Similarly, more than $70 \%$ of respondents disagreed with the statement $O$ ther people are friendly only because they want something out of me (item 19).

Their responses to statements 1, 2, 5, 6, and 7 showed that more than half the respondents were not afraid of and did not feel nervous in conversations in English class. They endorsed statements like I have no fears about expressing myself in a group (item $6,67.7 \%$ ), while rejecting the statement $I^{\prime} m$ afraid to speak up in conversations (item 1,67.9\%). Nevertheless, only $29.8 \%$ of the students agreed with the following: I talk a lot because I am not shy (item 3). This might reflect the students' mixed feelings about conversations. On one hand, they were willing to participate in conversations and were aware of the benefits of communication; however, they did not do so in practice for a variety of reasons. This mismatch is further evident in their responses to items 9 and 10. Only 20\% endorsed the statement During a conversation, I prefer to talk rather than listen (item 9), whereas 30.3\% reported that they find it easy to make conversation with strangers (item 10).

General tendency of the UCS. To determine the general tendency of the students' unwillingness to communicate, the total scores, means, and standard deviations of the UCS and its two subscales were computed. For items 
Table 1

UCS Items with Numbers and Percentages of Students Selecting Each Alternative $(\mathrm{N}=547)$

\begin{tabular}{llllll}
\hline$S D$ & $D$ & $N$ & $A$ & $S A$
\end{tabular}

1. I'm afraid to speak up in conversations.

$\begin{array}{lllll}69 / 12.6 & 290 / 53 & 79 / 14.4 & 102 / 18.7 & 7 / 1.3\end{array}$

2. I talk less because l'm shy.

$\begin{array}{lllll}63 / 11.5 & 229 / 41.9 & 99 / 18.1 & 149 / 27.2 & 7 / 1.3\end{array}$

3. I talk a lot because I am not shy.

$\begin{array}{lllll}14 / 2.6 & 213 / 38.9 & 157 / 28.7 & 137 / 25 & 26 / 4.8\end{array}$

4. I like to get involved in group discussions.

$\begin{array}{lllll}7 / 1.3 & 110 / 20.1 & 120 / 21.9 & 275 / 50.3 & 35 / 6.4\end{array}$

5. I feel nervous when I have to speak to others.

$\begin{array}{llll}33 / 6 & 252 / 46.1 & 104 / 19 & 150 / 27.4\end{array}$

6. I have no fears about expressing myself in a group.

$\begin{array}{lllll}5 / 0.9 & 85 / 15.5 & 87 / 15.9 & 337 / 61.7 & 33 / 6\end{array}$

7. I am afraid to express myself in a group.

$\begin{array}{lllll}46 / 8.4 & 339 / 62 & 86 / 15.7 & 70 / 12.8 & 6 / 1.1\end{array}$

8. I avoid group discussions.

$\begin{array}{lllll}75 / 13.7 & 315 / 57.6 & 97 / 17.8 & 57 / 10.4 & 3 / 0.5\end{array}$

9. During a conversation, I prefer to talk rather than listen.

$\begin{array}{lllll}14 / 2.6 & 265 / 48.4 & 159 / 29 & 93 / 17.1 & 16 / 2.9\end{array}$

10. I find it easy to make conversation with strangers.

$\begin{array}{lllll}32 / 5.9 & 217 / 39.7 & 132 / 24.1 & 151 / 27.6 & 15 / 2.7\end{array}$

11. I don't think my friends are honest in their communication with me.

$\begin{array}{lllll}37 / 6.8 & 250 / 45.8 & 168 / 30.7 & 78 / 14.3 & 14 / 2.6\end{array}$

12. My friends and family don't listen to my ideas and suggestions.

$\begin{array}{lllll}106 / 19.4 & 342 / 62.5 & 66 / 12.1 & 29 / 5.3 & 4 / 0.7\end{array}$

13. I think my friends are truthful with me.
$6 / 1.1$
$31 / 5.7$
124/22.7 332/60.6
$54 / 9.9$

14. I don't ask for advice from family or friends when I have to make decisions.

$$
\begin{array}{lllll}
79 / 14.4 & 330 / 60.3 & 65 / 11.9 & 57 / 10.4 & 16 / 3
\end{array}
$$

15. I believe my friends and family understand my feelings.
$9 / 1.6$
$48 / 8.8$
$116 / 21.2$
$320 / 58.5$
$54 / 9.9$

16. My family doesn't enjoy discussing my interests and activities with me.
$97 / 17.7$
$285 / 52.1$
95/17.4
$58 / 10.6$
$12 / 2.2$

17. My friends and family listen to my ideas and suggestions.

$\begin{array}{lllll}9 / 1.6 & 36 / 6.6 & 106 / 19.4 & 339 / 62 & 57 / 10.4\end{array}$

18. My friends seek my opinions and advice.
$6 / 1.1$
$39 / 7.1$
$117 / 21.4$
$350 / 64$
$35 / 6.4$

19. Other people are friendly only because they want something out of me.
$147 / 26.9$
$272 / 49.7$
$102 / 18.6$
$18 / 3.3$
$8 / 1.5$

20. Talking to other people is just a waste of time.
$175 / 32$
$317 / 58$
$35 / 6.4$
$16 / 2.9$
$4 / 0.7$

Notes. SD: Strongly disagree; D: Disagree; N: Neither disagree nor agree. 
that expressed willingness to participate and confidence in conversations, we adjusted the values assigned to alternatives from Strongly Disagree to Strongly Agree. For these items the response Strongly Disagree was given a value of 5 instead of 1, the response Strongly Agree was given a value of 1 instead of 5, and so forth. Thus the total score of the UCS revealed a respondent's general tendency not to communicate in conversations; the total score of AA represented a respondent's unwillingness to participate in interpersonal communication; and the total score of $\mathrm{R}$ reflected a respondent's negative attitudes toward speech communication. For all three constructs the higher the score, the less willing the student was to participate in conversations or to value speech communication highly. Because the UCS comprises 20 items with 10 items for each of its two subcomponents, a total score of more than 80 on the UCS implies that a respondent is strongly unwilling to participate in speech communication; a total score of 60-80 represents moderate unwillingness; and a score of less than 60 signifies moderate or even strong willingness to participate in speech communication. Similarly, a total score of more than 40 on RR or R suggests a strong unwillingness to participate in or a strongly negative attitude toward speech communication; a total score of 30-40 reflects moderate unwillingness or a moderately negative attitude; and a total score of less than 30 signifies strong or moderate willingness to participate in or a strongly or moderately positive attitude toward speech communication. The results are shown in Table 2.

Table 2 indicates that some students (those with a score of 90) wished very much to avoid speech communication. The mean score of 49.31 on the UCS, with a median of 49 and a mode of 46 , were all far below the scale midpoint 60 . This indicates that more than half the respondents were willing to participate in interpersonal interactions. This notion is further supported by the RR mean (27.05), median (27), and mode (25), which hardly exceeded the scale midpoint 30 . Meanwhile, a mean of 22.26 on $R$, together with a median of 22 and a mode of 20-all well below the scale midpoint 30-suggests that most of the participants were positive about speech communication and considered it worthwhile and useful.

In addition, the students' (un)willingness-to-communicate scores were consistent with their comments in their reflective journals. In their entries more than $70 \%$ of the students in each band group expressed a (strong)

Table 2

Statistical Analysis of the UCS ( $N=547)$

\begin{tabular}{lccccc}
\hline & Mean & Standard Deviation & Median & Mode & Range \\
\hline UCS & 49.31 & 8.83 & 49 & 46 & $24-90$ \\
AA & 27.05 & 5.77 & 27 & 25 & $10-46$ \\
R & 22.26 & 4.97 & 22 & 20 & $10-48$ \\
\hline
\end{tabular}


desire to learn and speak English well for various reasons (e.g., "English is important and useful," "speaking English well makes me more self-confident," "speaking English is a necessary ability for a university graduate"). The more proficient the students were in English, the more their journal entries expressed willingness to participate in English classroom activities. Table 3 indicates the frequency of these comments in their self-reports.

\section{Reticence Among Students at Various Proficiency Levels}

To determine if proficiency in English affected willingness to communicate, the means, standard deviations, modes, medians, and ranges of the UCS and its two subscales were computed for students at various band levels. The higher the score, the less willing the respondent was to participate in or to value speech communication. The results and further analyses are presented Tables 4, 5, and 6 .

As seen in Table 4, students in band 1 (the least proficient) not only had the highest minimum score of 26 on the UCS, but also the highest maximum score of 90 . By contrast, their band 3 (the most proficient) counterparts had both the lowest minimum score of 24 and the lowest maximum score of 77 on the UCS, and the band 2 students had these two scores in between. Results were nearly the same with the mean $(50.46,49.26$, and 48.15 for bands 1,2 , and 3 groups respectively), the median (50,49, and 47 for bands 1,2, and 3 students respectively), and the mode (44, 46, and 45 for bands 1, 2, and 3 students respectively). The analysis revealed similar results with AA and R: the band 1 group (27.66 on AA and 22.81 on R) scored the highest whereas their band 3 peers (26.57 on AA and 21.57 on R) reported the lowest scores on both scales. Clearly the band 1 students seemed to be the least willing, whereas their band 3 peers were the most willing to engage in conversations in English-language classrooms; and the band 1 group reported valuing interpersonal interactions the least, whereas their band 3 counterparts were the most positive about speech communication. That is, the more proficient in English the students were, the more willing they were to communicate with others in oral English class and the more they valued speech communication.

Table 3

Students' Expressed (Un)willingness to Communicate

\begin{tabular}{lcccc}
\hline Level & $\begin{array}{c}\text { No. of } \\
\text { participants }\end{array}$ & $\begin{array}{c}\text { Willingness to } \\
\text { speak English N (\%) }\end{array}$ & $\begin{array}{c}\text { Unwillingness to } \\
\text { speak English N (\%) }\end{array}$ & $\begin{array}{c}\text { Not mentioned } \\
\text { N (\%) }\end{array}$ \\
\hline Band 1 & 30 & $17(56.7 \%)$ & $7(23.3 \%)$ & $6(20 \%)$ \\
Band 2 & 31 & $22(71 \%)$ & $4(12.9 \%)$ & $5(16.1 \%)$ \\
Band 3 & 32 & $23(71.9 \%)$ & $1(3.1 \%)$ & $8(25 \%)$ \\
\hline
\end{tabular}


Table 4

Statistical Analyses of the UCS and its Subscales Across Levels

\begin{tabular}{lcccccc}
\hline & Level/No. & Mean & $\begin{array}{c}\text { Standard } \\
\text { Deviation }\end{array}$ & Median & Mode & Range \\
\hline UCS & $1(166)$ & 50.46 & 8.75 & 50 & 44 & $26-90$ \\
& $2(224)$ & 49.26 & 8.87 & 49 & 46 & $26-84$ \\
& $3(157)$ & 48.15 & 8.76 & 47 & 45 & $24-77$ \\
AA & $1(166)$ & 27.66 & 5.59 & 27 & 23 & $14-46$ \\
& $2(224)$ & 26.92 & 5.90 & 26 & 25 & $10-42$ \\
& $3(157)$ & 26.57 & 5.75 & 26 & 25 & $10-41$ \\
& $1(166)$ & 22.81 & 5.19 & 22 & 22 & $10-44$ \\
& $2(224)$ & 22.34 & 4.88 & 22 & 20 & $12-48$ \\
& $3(157)$ & 21.57 & 4.79 & 21 & 20 & $10-43$ \\
\hline
\end{tabular}

Nevertheless, the difference across the three groups in general was not significant, as indicated by the ANOVA results reported in Table 5. Because the results of the ANOVA were close to the conventional level of statistical significance in two of the three cases ( $p=.062$ for the UCS; $p=.079$ for R), post-hoc tests were undertaken to determine where the significant difference lay: Dunnett's procedure (which facilitates between-group comparisons of post-hoc tests) revealed a significant difference between the band 1 and the band 3 groups on the UCS (mean difference=2.32, $p=.034$ ) and R (mean difference $=1.23, p=.047$ ). As presented in Table 6, no significant difference was observed on any scale between the band 1 and the band 2 groups or between the band 2 and the band 3 groups. Proficiency did play a significant role in distinguishing the advanced-level from the low-level students in terms of their perceptions of the value of interpersonal communication. Nevertheless, it should be noted that the differences were not large, not much more than a quarter of a standard deviation unit.

\section{Student Reticence in Various Classroom Activities}

In the various activities (e.g., pair work, group discussions, and presentations) in class, the students had to speak English to varied audiences (in

Table 5

ANOVA Results of the UCS and its Subscales

\begin{tabular}{llllll}
\hline Measures & $\begin{array}{l}\text { Sum of } \\
\text { squares }\end{array}$ & $d f$ & Mean square & $F$ & $P$ \\
\hline UCS & 434.03 & 2 & 217.01 & 2.80 & .062 \\
AA & 100.31 & 2 & 50.16 & 1.51 & .222 \\
R & 125.16 & 2 & 62.58 & 2.55 & .079 \\
\hline
\end{tabular}


Table 6

Results of Multiple Comparisons of the UCS and its Subscales

\begin{tabular}{llccl}
\hline & & Mean difference & Standard error & $p$ \\
\hline \multirow{2}{*}{ UCS } & Bands 1 \& 2 & 1.20 & .90 & .306 \\
& Bands 2 \& 3 & 1.12 & .92 & .362 \\
& Bands 1 \& 3 & $2.32^{*}$ & .98 & .034 \\
AA & Bands 1 \& 2 & .73 & .59 & .353 \\
& Bands 2 \& 3 & .35 & .60 & .777 \\
& Bands 1 \& 3 & 1.08 & .64 & .161 \\
R & Bands 1 \& 2 & .47 & .51 & .55 \\
& Bands 2 \& 3 & .77 & .52 & .233 \\
& Bands 1 \& 3 & $1.23^{*}$ & .55 & .047 \\
\hline
\end{tabular}

Note. ${ }^{*}$ The mean difference is significant at the .05 level.

terms of size and composition): their reticence varied accordingly. This is shown in their comments in their reflective journals about their participation in various classroom activities. More than $60 \%$ of the students in each group self-reported as being the most active during pair work but the least active when responding to their teachers. This finding is reaffirmed in Table 7, which presents details of the students' reported participation in classroom activities during the first six weeks.

As can be seen from Table 7, each week most of the students in each band group self-reported as being more active during pair work than when asked questions by their teachers or during group work, which was seldom formally adopted by the teachers. Similarly, few of the student interviewees confided that they actively volunteered to respond to the teacher in class, although they were often encouraged to ask and answer questions. Nor would they challenge teachers or peer students in class (e.g., offer another opinion), as they had done when in middle school. On the other hand, most felt relaxed during pair work and group work. During pair work, those in bands 2 and 3 in particular usually kept speaking English until they exhausted their capacity to express their ideas on the topic. Then they either switched to Chinese or fell silent. A similar trend was observed by their teachers and was also evident in the videotaped observations. The band 2 teacher provided insight into this phenomenon in her interview.

The case is often like this: about 3 to 5 students are very active in classroom activities and actively respond to the teacher. About 20 students can perform well if the teacher asks them to answer questions or state personal ideas. If not asked, they remain silent. A few students remain extremely silent and just say "sorry, I don't know" even if asked by the teacher to say something about a topic. 
Table 7

Students' Self-Reported Participation in Classroom Activities

\begin{tabular}{lllllllllll}
\hline & \multicolumn{3}{c}{ Active during pair work } & \multicolumn{3}{c}{ Active to respond to the teacher } & \multicolumn{3}{c}{ Active during group work } \\
& $\begin{array}{l}\text { Band 1 } \\
N(\%)\end{array}$ & Band 2 & Band 3 & \multicolumn{2}{c}{ Band 1 } & Band 2 & Band 3 & Band 1 & Band 2 & Band 3 \\
& $N(\%)$ & $N(\%)$ & $N(\%)$ & $N(\%)$ & $N(\%)$ & $N(\%)$ & $N(\%)$ & $N(\%)$ \\
\hline Week 1 & $14(46.7 \%)$ & $12(38.7 \%)$ & $18(56.3 \%)$ & 0 & $4(12.9 \%)$ & $11(34.4 \%)$ & 0 & 0 & 0 \\
Week 2 & $17(56.7 \%)$ & $18(58.1 \%)$ & $20(62.5 \%)$ & $3(10 \%)$ & $6(19.4 \%)$ & $7(21.9 \%)$ & 0 & 0 & 0 \\
Week 3 & $21(70 \%)$ & $20(64.5 \%)$ & $25(78.1 \%)$ & $5(16.7 \%)$ & $4(12.9 \%)$ & $8(25 \%)$ & $4(13.3 \%)$ & $2(6.5 \%)$ & $4(12.5 \%)$ \\
Week 4 & $20(66.7 \%)$ & $20(64.5 \%)$ & $26(81.3 \%)$ & $3(10 \%)$ & $4(12.9 \%)$ & $9(28.1 \%)$ & 0 & 0 & $1(3.1 \%)$ \\
Week 5 & $25(83.3 \%)$ & $28(90.3 \%)$ & $25(78.1 \%)$ & $5(16.7 \%)$ & $5(16.1 \%)$ & $13(40.6 \%)$ & 0 & 0 & 0 \\
Week 6 & $23(76.7 \%)$ & $28(90.3 \%)$ & $30(93.6 \%)$ & $4(13.3 \%)$ & $6(19.4 \%)$ & $10(31.2 \%)$ & 0 & 0 & 0 \\
\hline
\end{tabular}

Note. Bands 1, 2, and 3 classes had 30, 31, and 32 journal participants respectively.

Furthermore, as the term progressed and the students gained more exposure to spoken English and became more used to interactive classroom activities, many changed from being quiet to being (more) active, a tendency not only reported by the students themselves, but also observed by their teachers. As shown in Table 7, only 4 band 2 and 11 band 3 students (and no band 1 students) reported that they actively responded to their teachers during the first lesson, although more $(14,12$, and 18 students from bands 1 , 2 , and 3 respectively) were active during pair work. From the second week on, however, more students in each band group tended to be active in oral English lessons and fewer were quiet, especially during pair work, although only a few more became more active in responding to their teachers' questions. The band 3 teacher in particular commented that by the end of the term few students were reticent during pair work.

As noted in Table 7, during each lesson more advanced-level students tended to be active during pair work than those who had a lower level of proficiency. The students reported the same trend when discussing their responses to teacher-initiated questions.

On the whole, not many students actively responded to their teachers, especially when the questions were challenging, as found in earlier studies (Cortazzi \& Jin, 1996; Jackson, 1999, 2002, 2003; Miller \& Aldred, 2000; Tsui, 1996). By contrast, most seemed to be active when speaking English with each other in pairs. The most reticent students hardly ever responded to their teachers' questions and made fewer contributions during pair work. When singled out to speak English, they often gave brief responses in a low voice, as observed by the teachers and ourselves. An interesting phenomenon was that some reticent students when interviewed informally in class described themselves as active because they attentively listened to their partners, like 
some of the students in Jackson's $(1999,2001)$ studies of Hong Kong university students in English-medium case discussions.

\section{Conclusions and Implications}

Based on the analyses and discussion presented above, the following conclusions can be reached. First, most of the students expressed a (strong) willingness to speak the target language in class and valued interpersonal interactions highly. The more proficient in English the students were, the more willing they were to participate in speech communication and the more positive they were about it. Despite this (strong) willingness and positive attitude, however, few students in each band group were observed to respond actively to the teacher in class, especially when the questions were difficult and / or challenging, as found in earlier studies (Cortazzi \& Jin, 1996; Jackson, 2001, 2003; Miller \& Aldred, 2000; Tsui, 1996). More students at a higher band level were observed and also self-reported being active in speaking English in class. The band 1 students (least proficient) were the least active, especially when responding to the teacher; the band 2 students actively participated in pair work and sometimes group discussions although few actively volunteered to answer questions; their band 3 (most proficient) counterparts were the most active and were supportive of each other in various classroom activities.

As for participation in classroom activities, pair work was the students' favorite, whereas presentations were the least preferred: in each band group most of the students were active during pair work, whereas only a few volunteered to respond to the teacher or give a presentation in front of the class. The most reticent students seldom contributed to discussion even during pair work. When required, their speeches tended to be short, like those in Evans' (1987) and Jackson's $(1999,2001)$ studies. However, with increasing exposure and access to spoken English, the students became more active in speaking the target language in classroom activities.

Clearly reticence is a serious and common phenomenon in English-language classes across all levels in this Mainland Chinese institution. In order to enhance students' participation and ultimately improve their fluency in the target language, both EFL teachers and students need to take some measures. As found in this study and many others (Park \& Oxford, 1998; Zou, 2004), students may remain reticent in class during the first few weeks and then gradually become more active after they have become familiar with the environment and classroom activities. Therefore, EFL teachers should clearly spell out the aims of the new communicative language teaching (CLT) style and explain specific course objectives. With a clear idea of course objectives and an understanding of teachers' and students' roles in CLT classrooms, students will be better positioned to adjust their own expecta- 
tions and goals. They will also have a better idea of what they need to do to be successful (Johnson, 1995).

It is also advisable for EFL teachers to create a relaxing, welcoming, and supportive classroom learning environment, as suggested in earlier studies of reticence in Asia (Tsui, 1996; Zou, 2004). To promote students' active participation in English-language lessons, it is also necessary for teachers to enhance students' interest in and motivation to speak the language. Scaffolding topics (e.g., giving a list of difficult vocabulary and sentence structures followed by role-playing) may help students feel more relaxed, less anxious, and more willing to participate (e.g., to state their opinions in a group, Prégent, 1994).

To understand reticence better in second- or foreign-language classrooms, more research employing both quantitative and qualitative methods needs to be carried out with varied groups of learners in a variety of environments. Future studies should explore the multiple causes of reticence and explore potential coping strategies to help students become more confident, active learners of the target language. In particular, studies of a longitudinal nature are needed to gain a better understanding of students' reticence and willingness over time to communicate in oral situations. This would provide a more complete picture of the learning situation as learners' proficiency level (and confidence) grows. Ultimately, the findings should improve the language-learning experiences of even the most reticent students.

\section{Note}

${ }^{1}$ The students were placed into band groups ranging from 1-3 (band 1 was the lowest and band 3 the highest) on the basis of a placement test administered when they entered the University.

\section{Acknowledgment}

This project was funded by Research in Humanities and Social Sciences, the Chinese Ministry of Education (the Youth Fund-06JC740010) in 2006.

\section{The Authors}

Meihua Liu is a lecturer of English in the Department of Foreign Languages, Tsinghua University, China. Her research interests include EFL teaching and learning in the Chinese context, classroom research, and second-language writing.

Jane Jackson, who completed her doctorate at OISE/University of Toronto, is a professor in the English Department of the Chinese University of Hong Kong. Her research interests include intercultural communication or pragmatics, reticence and anxiety in L2 learners, identity reconstruction, and student residence abroad. Recent books include Language, Identity, and Study Abroad: Sociocultural Perspectives (Equinox, 2008) and Becoming Intercultural: From Study to Residence Abroad (Palgrave MacMillan, 2009).

\section{References}

Burgoon, J. (1976). The Unwillingness-to-Communicate scale: Development and validation. Communication Monographs, 43, 60-69. 
Burgoon, J., \& Koper, R. (1984). Nonverbal and relational communication associated with reticence. Human Communication Research, 10, 601-626.

Chen, T. (2003). Reticence in class and on-line: Two ESL students' experiences with communicative language teaching. System, 31, 259-281.

Cortazzi, M., \& Jin, L. (1996). Cultures of learning: language classrooms in China. In H. Coleman (Ed.), Society and the language classroom (pp. 169-206). Cambridge, UK: Cambridge University Press.

Evans, M. A. (1987). Discourse characteristics of reticent children. Applied Psycholinguistics, 8, 171-184.

Flowerdew, J., Miller L., \& Li, D. (2000). Chinese lecturers' perceptions, problems and strategies in lecturing in English to Chinese-speaking students. RELC Journal, 31(1), 116-138.

Jackson, J. (1999). Perceptions of Chinese students in an English-medium case-based management course. In H. Klein (Ed.), Interactive teaching and the multimedia revolution: case method and other techniques (pp. 61-76). Boston, MA: World Association for Case Method Research and Application.

Jackson, J. (2001). Combating dead air in case discussions. In H. Klein (Ed.), Complex demands on teaching require innovation: Case method and other techniques (pp. 227-240). Boston, MA: World Association for Case Method Research and Application.

Jackson, J. (2002). Reticence in second language case discussions: Anxiety and aspirations. System, 30(1), 65-84.

Jackson, J. (2003). Case-based learning and reticence in a bilingual context: perceptions of business students in Hong Kong. System, 31, 457-469.

Johnson, G. (1995). First steps to excellence in college teaching. Madison, WI: Magna Publications.

Krippendorff, K. (1980). Content analysis: an introduction to its methodology. Beverly Hills, CA: Sage.

Liu, M. (2006a). Reticence in oral English classrooms: Causes and consequences. Asian Journal of English Language Teaching, 16, 45-66.

Liu, M. (2006b). Anxiety in Chinese EFL students at different proficiency levels. System, 34(3), 301-316.

Liu, M. (2007). Anxiety in oral English classrooms: A case study in China. Indonesian Journal of English Language Teaching, 3(1), 119-137.

Liu, M., \& Jackson, J. (2007). Reticence in Chinese English classrooms-An investigation of the Unwillingness-to-Communicate scale. Teaching in China (4): Proceedings of the 4th Teaching in China. Beijing: Beijing Teaching and Research Press.

Liu, M., \& Jackson, J. (2008). An exploration of Chinese EFL learners' unwillingness to communicate and foreign language anxiety. Modern Language Journal, 92(1), 71-86.

Liu, N., \& Littlewood, W. (1997). Why do many students appear reluctant to participate in classroom learning discourse? System, 25(3), 371-384.

MacIntyre, P.D., Baker, S.C., Clément, R., \& Conrod, S. (2001). Willingness to communicate, social support, and language-learning orientations of immersion students. Studies in Second Language Acquisition, 23, 369-388.

Miller, L., \& Aldred, D. (2000). Student teachers' perceptions about communicative language teaching methods. RELC Journal, 31(1), 1-22.

Park, Y., \& Oxford, R. (1998). Changing roles for teachers in the English Village Course in Korea. System, 26(1), 107-113.

Prégent, R. (1994). Charting your course: How to prepare to teach more effectively. Madison, WI: Magna Publications.

Thein, M. (1994). A non-native English speaking teachers' response to a learner-centered program. System, 22(4), 463-471. 
Tsui, A. (1996). Reticence and anxiety in second language learning. In K.M. Bailey \& D. Nunan (Eds.), Voices from the language classroom: Qualitative research in second language education (pp. 145-167). Cambridge, UK: Cambridge University Press.

Zou, M. (2004). EFL learners' perceptions of in-class relationships and their voluntary responses. In Y. Gao (Ed.), The social psychology of English learning by Chinese college students (pp. 149-167). Beijing: Foreign Language Teaching and Research Press. 